\title{
MODEL ORDER REDUCTION OF BOLTING AND FEASIBILITY EVALUATION
}

\author{
SIDDHARTH GHOSH ${ }^{1}$, SWATHI REDDY S. $\mathbf{R}^{2}$, \\ BENJAMIN ROHIT $^{3} \&$ MANUSHREE CHATURVEDI ${ }^{4}$ \\ ${ }^{1,2,3}$ R. V. College of Engineering, Bangalore, India \\ ${ }^{4}$ PESIT-BSC, Bangalore, India
}

\begin{abstract}
The main idea in the present age, is to improve efficiency of computation, by reducing computational space and time eventhough, we have high end computing power. It is still preferred to use minimum computation time and space. We have attempted in this study, to try and reduce a $3 D$ bolt model, to a $2 D$ model, by using the plane stress approach. The objective of the present study is to evaluate the feasibility of reducing the $3 D$ model, into $2 D$.

The requirements of the $2 D$ Bolt, is to match the mass of the actual bolt, and to match the axial and bending stiffness of the actual bolt, and simulate the effects of $3 D$ bolt in 2D, as close as possible to $3 D$ including contact pressures. Symmetry conditions have been used on the cylinder. Elements and meshes have been discussed, and the best technique to simulate the $3 D$ bolt in $2 D$, has been proposed.

KEYWORDS: Plane Stress, Model Order Reduction \& Contact Pressures
\end{abstract}

Received: Jul 29, 2017; Accepted: Aug 17, 2017; Published: Sep 16, 2017; Paper Id.: IJMPERDOCT201723

\section{INTRODUCTION}

In this paper, a high-strength grade 8.8 bolt, made from low carbon steels or alloy steels, with dimensions as shown in the figure [1], in accordance with BS 4190:2001 and BS EN ISO 4014:2001, was taken into consideration. Comparison of theoretical results and numerical results has been made, for both tension and bending analysis. Mesh sensitivity was performed, to obtain mesh independent result. All the analysis was done, using Ansys Mechanical APDL.

Main objective of this paper, is to match the results of 3D analysis with 2D analysis. To do so, we use a plane stress method, in which principle stresses and strains in one particular direction is assumed to be zero. We match the mass and moment of inertia of the actual bolt, with the required $2 \mathrm{D}$ bolt, to get the dimensions of a $2 \mathrm{D}$ bolt and simulate the effects of 3D bolt, in $2 \mathrm{D}$. Here, we check how close the results match with the 3D bolt analysis.

A nonlinear analysis, in both 3D and 2D has been done, and results such as contact pressure and principle stresses are compared, to see whether they match, and different methods have been adopted to make sure, the error percentage between obtained results and analytical results are reduced. There is very little literature available in this field of research, which is the reason for few references in the end of this paper. 


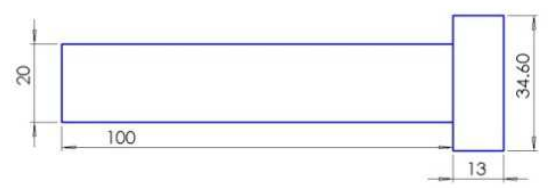

Figure 1: Dimensions of the Bolt Model

\section{AXIAL DEFORMATION}

Axial deformation can be through tension or compression. A high-strength grade 8.8 bolt, made from low carbon steels with Young's modulus, and Poisson's ratio, as $200 \mathrm{GPa}$ and 0.3 and with dimensions based on [1], is selected for the analysis, throughout the paper. To conduct the analysis, theoretical deflection is calculated by applying a tensile load of $216.1 \mathrm{Kn}$ [1]. Total theoretical deflection was found out to be 0.3588691 . This deflection is compared with the numerical results. During analysis, both tetrahedral and hexagonal elements are used and compared, for best result accuracy. Under tetrahedral, elements like - SOLID 285, 187, 92, 72 were used. Under hexagonal, elements like - SOLID 185, 186, 95, 45 were used. The solid 180 elements are applicable for Elastic to Hyper-elastic, to Visco-elastic materials [2]. Table 1 and 2 shows, the analysis under hexagonal mesh and tetrahedral mesh, respectively. It has been found in literature that, hexagonal meshes tend to be more accurate than tetrahedral meshes [3].

\section{HEX MESH -DEFLECTION VS TIME}
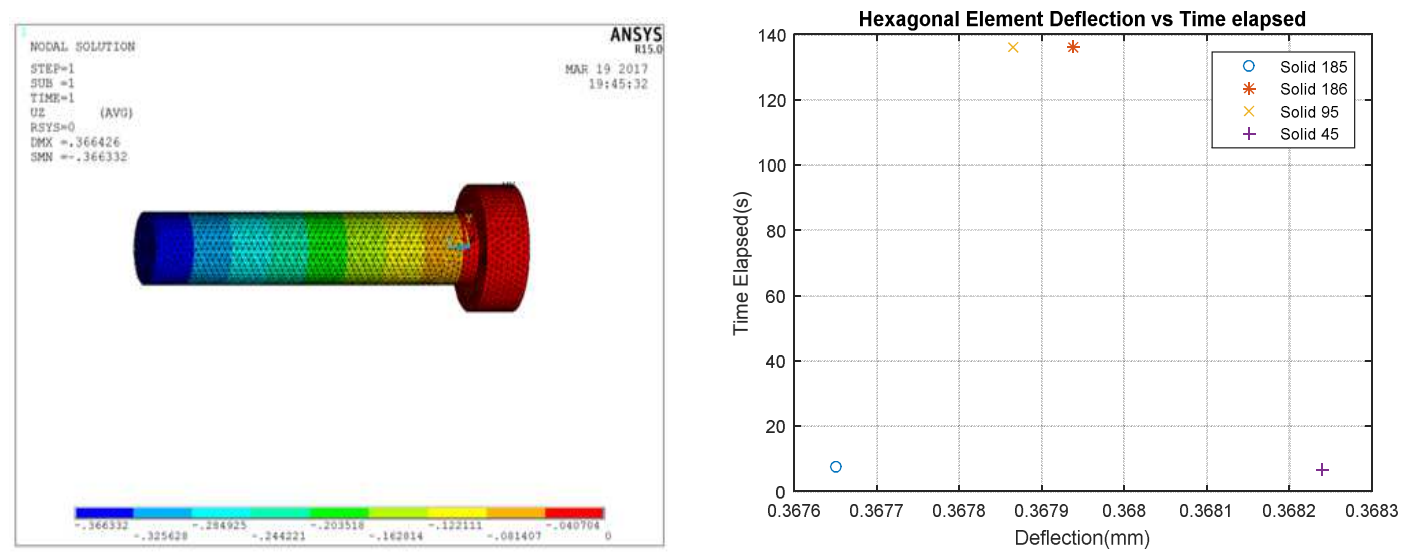

Figure 2: Accuracy and Time Efficiency of the Hexagonal Mesh

Table 1: Comparison Table for Hexagonal Elements

\begin{tabular}{|c|c|c|c|c|c|c|c|c|}
\hline \multicolumn{9}{|c|}{ Position Fixed : Bolt Head Pressure Applied = 687.8682Mpa Element Type = Hexagonal } \\
\hline \multirow{2}{*}{$\begin{array}{c}\text { Element } \\
\text { Type }\end{array}$} & \multicolumn{2}{|c|}{ Element Results } & \multirow{2}{*}{$\begin{array}{l}\text { C.P.U } \\
\text { Time } \\
\text { (Sec) }\end{array}$} & \multirow{2}{*}{$\begin{array}{l}\text { Elapsed } \\
\text { Time } \\
\text { (Sec) }\end{array}$} & \multirow{2}{*}{$\begin{array}{c}\text { Memory } \\
\text { Used } \\
(\mathbf{m b})\end{array}$} & \multirow{2}{*}{$\begin{array}{l}\text { Deflection } \\
(\mathrm{Mm})\end{array}$} & \multirow{2}{*}{$\begin{array}{l}\text { Stress } \\
\text { (Von } \\
\text { Mises) } \\
\text { (Mpa) }\end{array}$} & \multirow{2}{*}{$\begin{array}{c}\text { No. of } \\
\text { Equations }\end{array}$} \\
\hline & $\begin{array}{l}\text { C.P.U } \\
\text { Time } \\
\text { (Sec) } \\
\end{array}$ & $\begin{array}{c}\text { Elapsed } \\
\text { Time } \\
(\mathrm{Sec})\end{array}$ & & & & & & \\
\hline Solid 185 & 8.073 & 1.58 & 12.527 & 7.65 & 897.327 & 0.367651 & 1253.38 & 112395 \\
\hline Solid 186 & 2.59 & 1.301 & 130.916 & 136.304 & 895.249 & 0.367938 & 1659.72 & 320838 \\
\hline Solid 95 & 1.342 & 0.722 & 130.417 & 136.225 & 895.249 & 0.367865 & 1609.96 & 320838 \\
\hline Solid 45 & 1.544 & 0.781 & 11.878 & 6.773 & 871.088 & 0.36824 & 1352.11 & 111654 \\
\hline
\end{tabular}




\section{TET-DEFLECTION VS TIME}
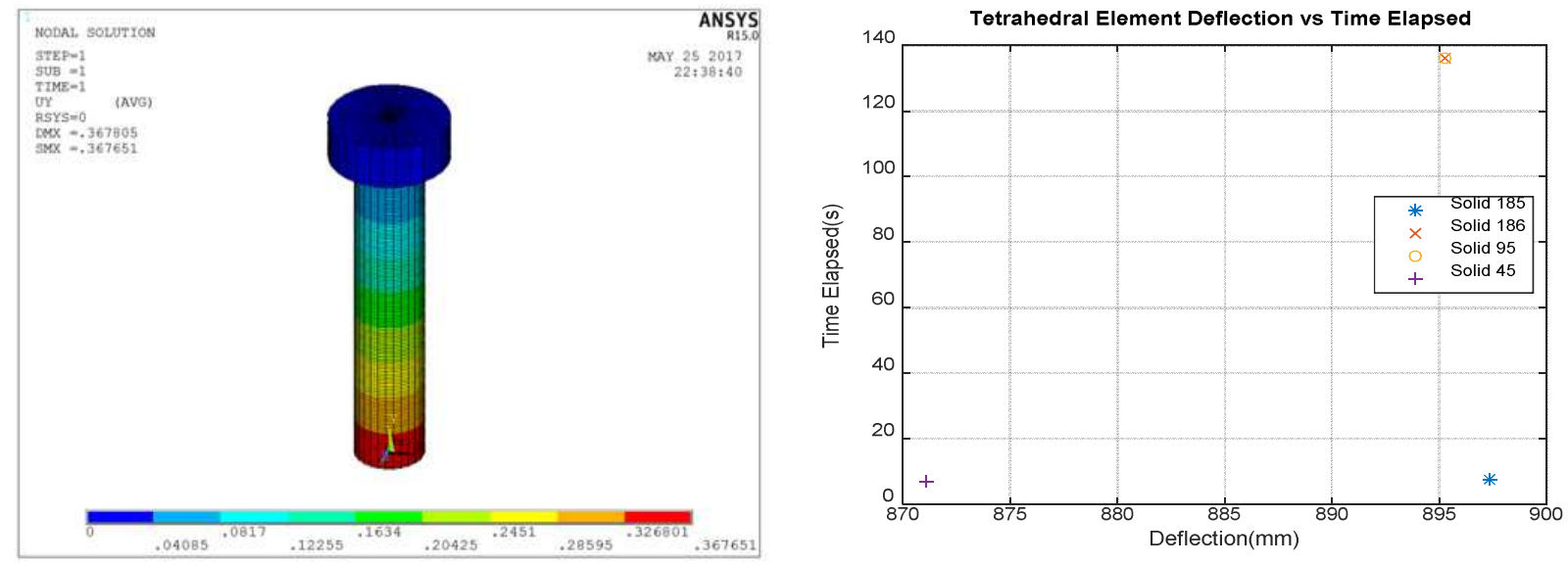

Figure 3: Accuracy and Time Efficiency of the Tetrahedral Mesh

Table 2: Comparison Table for Tetrahedral Elements

\begin{tabular}{|c|c|c|c|c|c|c|c|c|}
\hline \multicolumn{9}{|c|}{ Position fixed : Bolt head Pressure applied $=687.8682 \mathrm{Mpa}$ Type $=$ Tetrahedral } \\
\hline \multirow{2}{*}{$\begin{array}{c}\text { Element } \\
\text { Type }\end{array}$} & \multicolumn{2}{|c|}{ Element Results } & \multirow{2}{*}{$\begin{array}{l}\text { C.P.U } \\
\text { Time } \\
\text { (Sec) }\end{array}$} & \multirow{2}{*}{$\begin{array}{c}\text { Elapsed } \\
\text { Time } \\
\text { (Sec) }\end{array}$} & \multirow{2}{*}{$\begin{array}{c}\text { Memory } \\
\text { Used } \\
\text { (Mb) }\end{array}$} & \multirow{2}{*}{$\begin{array}{l}\text { Deflection } \\
(\mathrm{Mm})\end{array}$} & \multirow{2}{*}{$\begin{array}{c}\text { Stress } \\
\text { (Von Mises) } \\
\text { (Mpa) }\end{array}$} & \multirow{2}{*}{$\begin{array}{c}\text { No. of } \\
\text { Equations }\end{array}$} \\
\hline & $\begin{array}{l}\text { C.P.U } \\
\text { Time } \\
\text { (Sec) }\end{array}$ & $\begin{array}{c}\text { Elapsed } \\
\text { Time } \\
\text { (Sec) }\end{array}$ & & & & & & \\
\hline Solid 185 & 5.678 & 2.839 & 6.521 & 3.589 & 288.841 & 0.366336 & 1098.97 & 47224 \\
\hline Solid 186 & 4.087 & 2.034 & 45.225 & 25.177 & 2425.903 & 0.367677 & 1595.12 & 265947 \\
\hline Solid 95 & 1.544 & 0.836 & 58.937 & 41.566 & 369.539 & 0.367677 & 1595.12 & 265947 \\
\hline Solid 45 & 3.323 & 1.695 & 7.004 & 3.895 & 535.033 & 0.366504 & 1082.67 & 71358 \\
\hline
\end{tabular}

By the graphs shown in figure [2, 3], and from the table [1,2], we can conclude that, best results are obtained by solid 185(hexagonal), with deflection of 0.366336 , with error of $2.08 \%$ and solid 285 (tetrahedral), with deflection of 0.367561 and error of $2.42 \%$. Hence, the best element type is solid 285 (under tetrahedral), and solid 185 (under hexagonal), with respect to number of equations, time taken and accuracy.

\section{BENDING DEFLECTION}

For bending analysis a load of $216.1 \mathrm{kN}$ [1], is applied on the bolt shank transversely, keeping the head fixed as in figure 4 . The deflection is compared between theoretical and numerical deflection.

While simulating the results, the element chosen is from the above tensile analysis, in which solid 185 (hexagonal) and solid 285 (tetrahedral), gave best results, with respect to time taken and accuracy, in deflection. The deflection was found to be $.051463 \mathrm{~mm}$. These results are further compared with 2D analysis results, in further sections. 


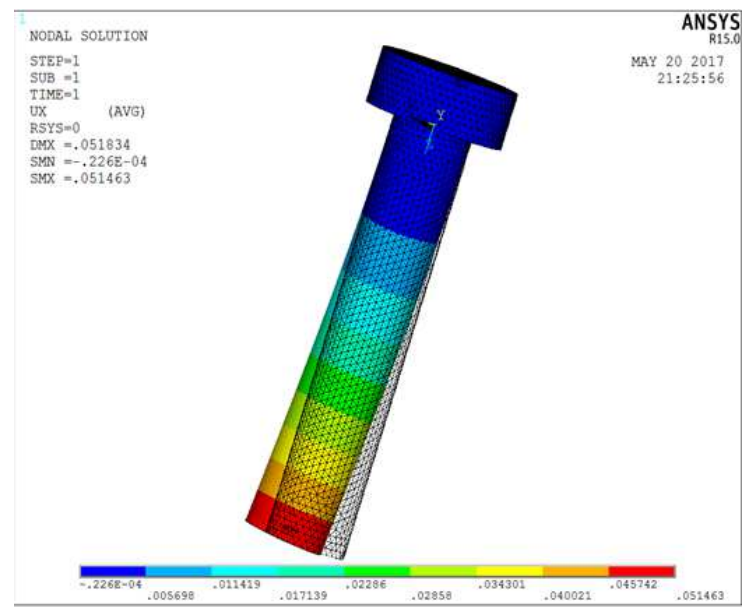

Figure 4: Bending of the Bolt

\section{D TO 2D}

The objective of this study was to reduce a $3 \mathrm{D}$ analysis to $2 \mathrm{D}$ analysis, with the same accurate results, which saves time taken for analysis and the computational space required. The number of equations solved, also was found out to be less in 2D analysis, when compared to 3D. So, for this purpose plane stress method is used, in which stress vector in one direction is considered to be zero. The compatibility of the $3 \mathrm{D}$ bolt to $2 \mathrm{D}$ bolt, is done by either using equivalent area method or equivalent moment of inertia. During this model reduction and simplification, we could have a problem of error, if we do not make the appropriate assumptions, and other source of error could be due to improper discretization, if a course mesh is used, the mesh and model will not capture the stiffness of the component correctly [4]. Hence, a mesh independent result needs to be obtained.

\section{D Axial Deformation}

Modeling 2D bolt, for axial deformation is done, by taking the equivalent area of 3D bolt to find the thickness required. The area of both $2 \mathrm{D}$ and $3 \mathrm{D}$ bolts, are equated to find the thickness. From analytical calculations, where we equate the area of the $3 \mathrm{D}$ bolt head, to the area of the $2 \mathrm{D}$ bolt head, we get $\mathrm{t}_{1}=27.17477 \mathrm{~mm}$. The bolt head is modeled in plane 182, using this thickness ' $\mathrm{t}_{1}$ ' and width as $34.6 \mathrm{~mm}$, and similarly, the area of the 3D bolt shank and area of 2D bolt shank, are equated and we obtain $t_{2}=15.7 \mathrm{~mm}$. The bolt shank is modeled, using this thickness ' $t_{2}$ ' and width as $20 \mathrm{~mm}$.

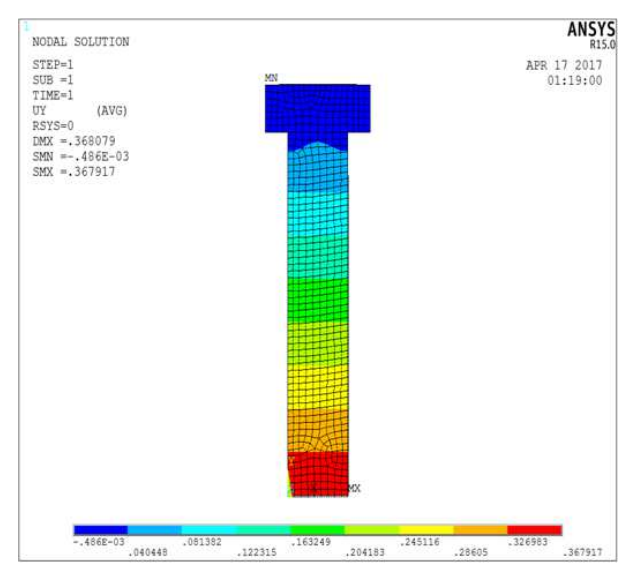

Figure 5: Bottom Head Constraint Model

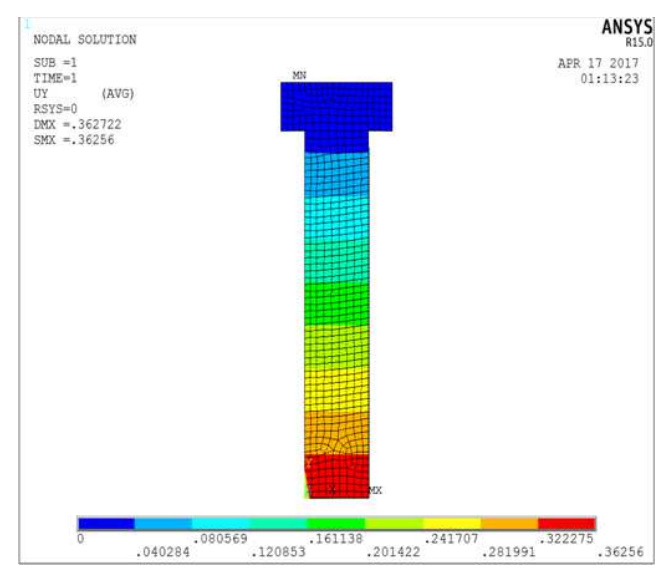

Figure 6: Upper Head Constraint Model

Two cases were considered, where in, the first case the bottom part of the head was fixed as shown in figure [5]. 
The different bolting conditions were discussed by Jerome Montgomery, from Siemens Westinghouse Power Corporation, Orlando, FL [5].The deflection was found out to be $0.367917 \mathrm{~mm}$, with an error of $2.52 \%$, compared to 3D model.

In the second case, upper part of the bolt head is fixed as shown in figure [6], and the load is applied axially to the bolt, and a deflection of 0.36256 is obtained. By comparing this value with the 3D analysis, we found out there is $1.0284 \%$ error, which is very minimum and also conforms the compatibility of the conversion $3 \mathrm{D}$ bolt, into $2 \mathrm{D}$ analysis.

\section{D BENDING}

In $2 \mathrm{D}$ bending, the bolt is modeled by equating the equivalent moment of inertia of $3 \mathrm{D}$ model. By doing this, we find out the thickness required to model the bolt. We use the same approach, as in the previous section and hence, we can obtain $\mathrm{d}=29.004 \mathrm{~mm}$

Thus, the bolt head is modeled using the thickness $29.004 \mathrm{~mm}$. The thickness of the shank is found to be D $=19.8776 \mathrm{~mm}$.

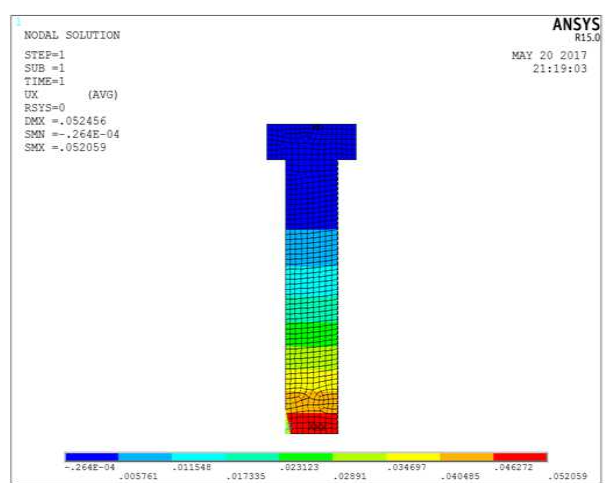

Figure 7: Lateral Deflection in the Bolt Model

Using these thicknesses, the bolt is modeled and load of $216.1 \mathrm{kN}$ is applied transversely. The deflection obtained is 0.52059 , as shown in figure [7], which is compared to 3D deflection that has an error percentage of $1.158 \%$.

\section{NON LINEAR ANALYSIS}

Here, a flange is used to produce nonlinear loading conditions. The boundary conditions, which are symmetric about the axis of the flange are set to satisfy convergence criteria. The analysis is done, for varying values of coefficient of friction. The bolt is bonded to the flange, and a pressure of $100 \mathrm{mpa}$ is applied, for all numerical analysis. The main parameters measured were von mises stress, and contact pressure. The setup is shown in figure [8].

Symmetry conditions have been used, on the cylinder and thus, only $180^{\circ}$ model has been considered. So, a lateral constraint has been applied on the symmetry face, and one node on the cylinder flange mid plane of the lower casing has been constrained, to move in vertical direction. This is purely a FE convergence requirement, as shown in figure [9]. 


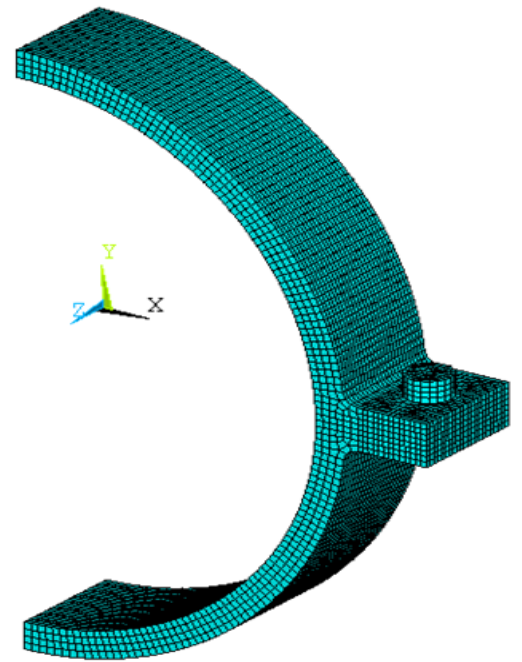

Figure 8: Setup of Bolt and Flange for Non Linear Analysis

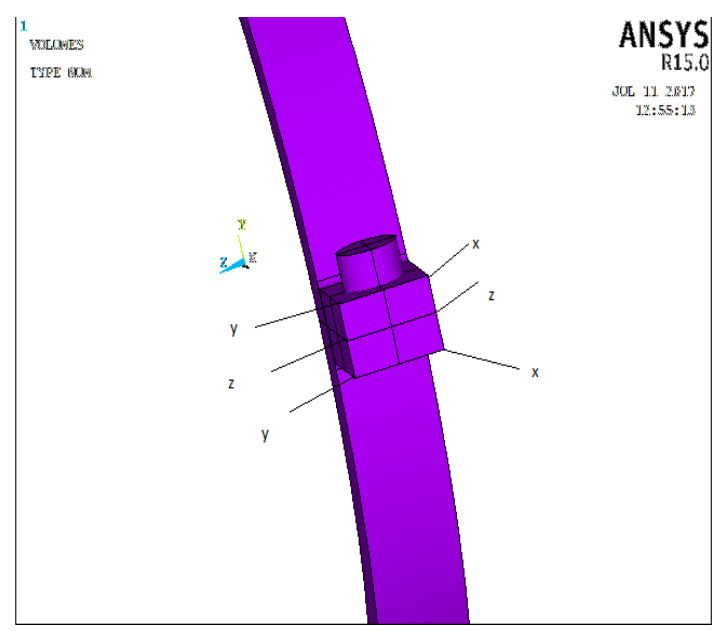

Figure 9: FE Convergence Requirement

\section{D EQUIVALENT AREA IN 3D FOR THE NON LINEAR SETUP}
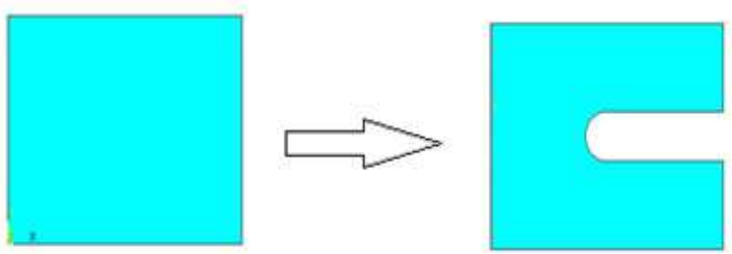

\section{Figure 10: Reduction of Effective Flange Area}

It is seen that, for the $2 \mathrm{~d}$ analysis, the effective flange area is reduced by 1.27 times its original area, as shown in figure [10]. Hence, the bolt is converted to its equivalent $2 \mathrm{~d}$ model, where the thickness of the bolt is equal to 1.27 times the diameter of the bolt head and shank, respectively.

\section{COMPARISON OF 3D AND 2D RESULTS}

The computational time and memory space, required between 3D and 2D analysis, is shown in the table [3]

Table 3: Computational Time and Memory Efficiencies in 2D and 3D Case

\begin{tabular}{|l|c|c|c|}
\hline \multicolumn{1}{|c|}{ Model Type } & $\begin{array}{c}\text { CPU Time } \\
\text { (Sec) }\end{array}$ & $\begin{array}{c}\text { Elapsed Time } \\
(\mathbf{S e c})\end{array}$ & $\begin{array}{c}\text { Memory } \\
(\mathbf{M b})\end{array}$ \\
\hline 3D & 16.75 & 10.534 & 591.656 \\
\hline 2D & 0.094 & 0.046 & 15.259 \\
\hline Percentage decrease & $99.438 \%$ & $99.5633 \%$ & $97.42 \%$ \\
\hline
\end{tabular}

The $2 \mathrm{~d}$ analysis was $99.5633 \%$ faster and saved about $97.42 \%$ data, compared to its $3 \mathrm{~d}$ counterpart. The von mises stress values of the $2 \mathrm{~d}$ model was found to be in good accordance with the $3 \mathrm{~d}$ model, for coefficient of friction values, varying from 0.1 to 0.8 .The error being a max of $0.027 \%$. 


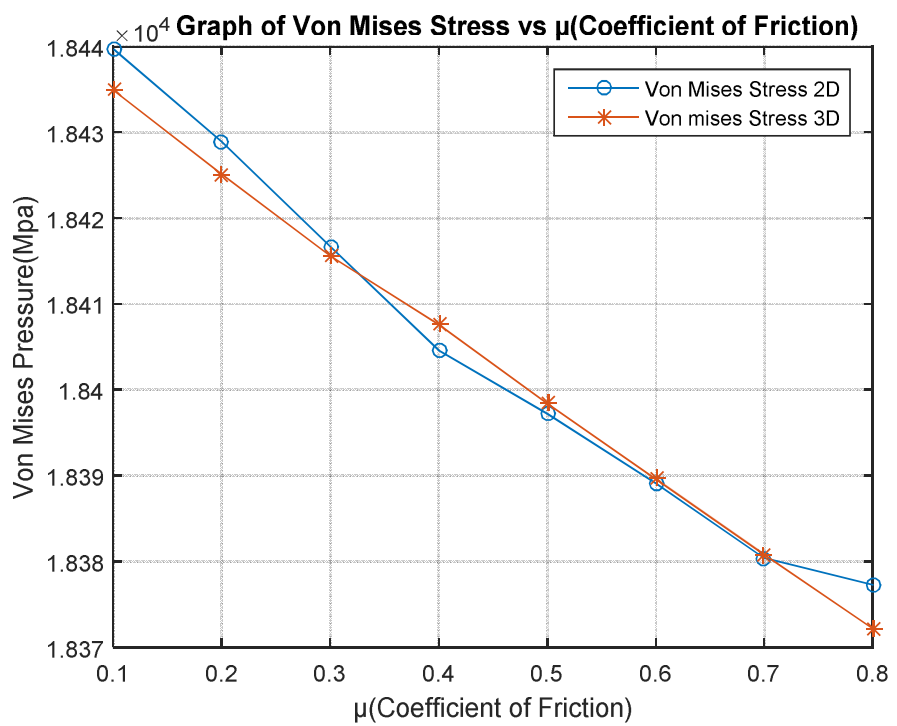

Figure 11: Graph of Von Mises Pressure Vs Coefficient of Friction in 2D and 3D

Table 4: Variation of Contact Pressures between 2D and 3D

\begin{tabular}{|c|c|c|}
\hline $\boldsymbol{\mu}$ (Coefficient of Friction) & $\begin{array}{c}\text { Von Mises Stress (3d) } \\
\text { mpa }\end{array}$ & $\begin{array}{c}\text { Von Mises Stress (2d) } \\
\text { mpa }\end{array}$ \\
\hline 0.1 & $18,434.90$ & 18439.7 \\
\hline 0.2 & 18425.1 & 18428.9 \\
\hline 0.3 & 18415.6 & 18416.7 \\
\hline 0.4 & 18407.6 & 18404.6 \\
\hline 0.5 & 18398.4 & 18397.2 \\
\hline 0.6 & 18389.6 & 18389.1 \\
\hline 0.7 & 18380.8 & 18380.4 \\
\hline 0.8 & 18372.2 & 183377.3 \\
\hline
\end{tabular}

The Contact pressure, von mises values were similar between $3 \mathrm{D}$ and $2 \mathrm{D}$ analysis, with identical pressure distribution along the axis of the flange and the bolt as shown in the table [4] and figures [11, 12, 13, and 14]. The slight variation of the values can be accounted to the nonlinear distribution of contact pressure.

The two peaks in each simulation i.e., $2 \mathrm{~d}$ and $3 \mathrm{~d}$ correspond to contact pressure, on the two surfaces of the bolt. Graph of contact pressure distribution, along the vertical axis the flange passing through the center of the bolt, is shown in figure $[12,13]$.

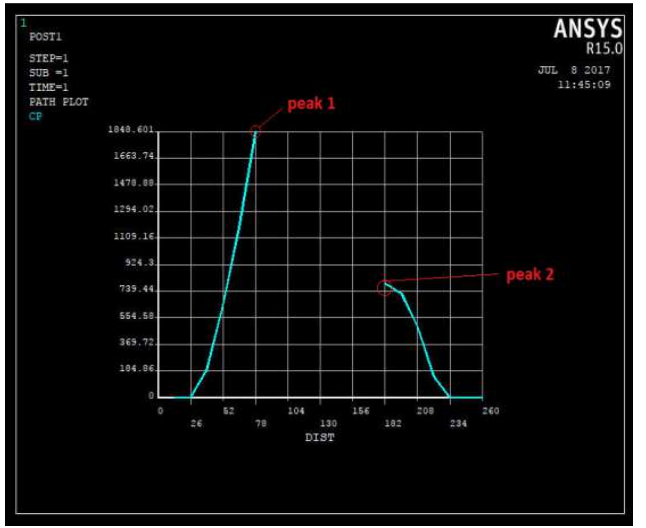

Figure 12: Contact Pressures for 2D Flange Analysis

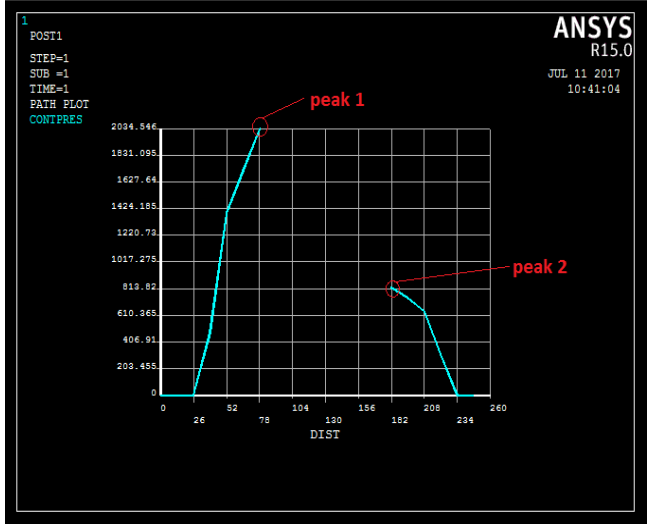

Figure 13: Contact Pressures for 3D Flange Analysis 


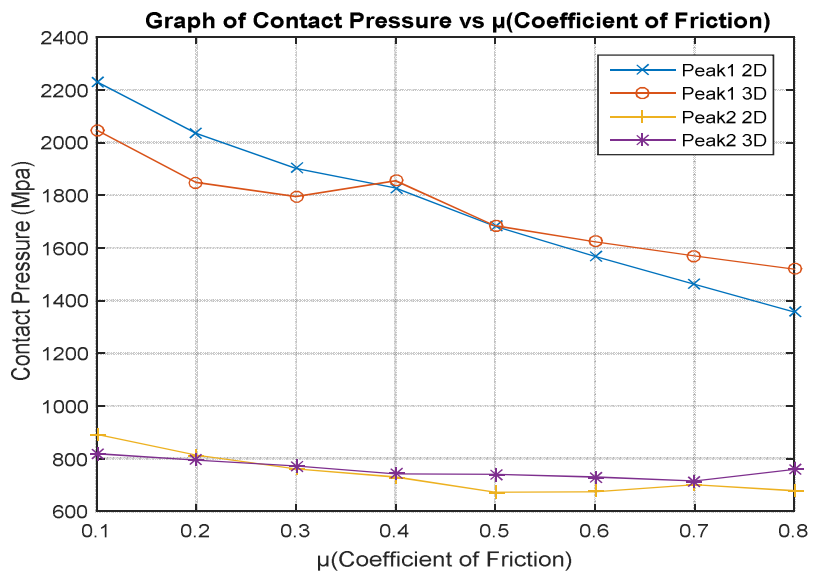

Figure 14: Graph of Contact Pressure Vs Coefficient of Friction

Table 5: Comparison of Contact Pressures of 2D and 3D Analysis

\begin{tabular}{|c|c|c|c|c|}
\hline $\begin{array}{c}\boldsymbol{\mu} \text { (Coefficient } \\
\text { of Friction) }\end{array}$ & $\begin{array}{c}\text { Contact Pressure } \\
\text { Peak1 (2d) }\end{array}$ & $\begin{array}{c}\text { Contact } \\
\text { Pressurepeak1 (3d) }\end{array}$ & $\begin{array}{c}\text { Contact } \\
\text { Pressurepeak2 (2d) }\end{array}$ & $\begin{array}{c}\text { Contact } \\
\text { Pressurepeak2 (3d } \\
\text { ) }\end{array}$ \\
\hline 0.1 & 2230.643 & 2047.736 & 892.256 & 819.096 \\
\hline 0.2 & 2034.549 & 1848.601 & 813.82 & 794.898 \\
\hline 0.3 & 1902.2 & 1794.992 & 760.88 & 771.996 \\
\hline 0.4 & 1826.898 & 1854.729 & 730.76 & 741.892 \\
\hline 0.5 & 1681.454 & 1684.041 & 672.58 & 740.976 \\
\hline 0.6 & 1568.312 & 1623.475 & 674.373 & 730.566 \\
\hline 0.7 & 1461.792 & 1569.531 & 701.659 & 759.069 \\
\hline 0.8 & 1356.84 & 1519.233 & 678.42 & \\
\hline
\end{tabular}

\section{CONCLUSIONS}

In this paper, linear analysis of the bolt under tension/compression, bending loads was conducted. Comparison of 3D and 2D model was done, using the best solid element, which reduced the time and memory space required for the analysis. In nonlinear analysis, von mises stress and contact pressure, were compared with 3D results and equivalent area in 2D was found, which gave similar results with low error percentage. This reduced the computation time and memory, used in numerical analysis, hence, optimizing the 3D model to an equivalent 2D model.

\section{REFERENCES}

1. Ying Hu, Le Shen, ShidongNie, Bo Yang, Wei S5Jha, FE simulation and experimental tests of high-strength structural bolts under tension, Journal of Constructional Steel Research, Vol126, Pp 174-186,Nov 2016.

2. Mechanics \& Simulation Support Group, 180 Series elements: Why should one use them in Linear Analysis, Ansys conference proceedings (URL: http://ansys.net/papers/nonlinear/180xAdvantages.pdf).

3. A comparison of all-Hexahedra and all Tetrahedral Finite Element Meshes for elastic \& elastoplatic analysis. Proceedings $4^{\text {th }}$ International Meshing Round table Sandia National Labs, pp 179-181, Oct. 1995.

4. Chandresh Shah, Cummins, Inc, Mesh Discretization Error and Criteria for Accuracy of Finite element Solutions, Ansys conference proceedings (URL: http://ansys.net/papers/9.pdf)

5. Jerome Montgomery, Siemens Westinghouse Power Corporation, Orlando, FL, Methods for Modeling Bolts in the Bolted Joint, Ansys Conference Proceedings (http://ansys.net/papers/nonlinear/methods_for_modeling_bolts.pdf) 